\title{
PENELITIAN
}

\section{PENGETAHUAN IBU PASKA MELAHIRAKAN TENTANG PIJAT BAYI DI KOTA BANDAR LAMPUNG}

\author{
Riyanti Imron*, Putri Wardarita* \\ Jurusan Kebidanan Poltekkes Tanjungkarang \\ E-mail: riyantiimron74@gmail.com
}

\begin{abstract}
Pijat bayi merupakan tradisi turun temurun yang mampu membantu mengoptimalkan tumbuh kembang bayi. Informasi dan pengetahuan yang kurang, menyebabkan sebagian orangtua beranggapan bahwa pijat bayi dilakukan hanya pada bayi yang sakit serta dilakukan oleh tukang pijat atau tenaga medis yang menguasai pijat. Tujuan dalam penelitian adalah untuk mengetahui gambaran pengetahuan ibu tentang pijat bayi di PMB Nurmala Dewi Bandar Lampung. Metode Penelitian ini menggunakan pendekatan deskritif kuantitatif dengan pendekatan cross sectional. Sampel Penelitian berjumlah 30 orang dengan metode acidental sampling, Instrumen penelitian berupa kuesioner tertutup. Analisa data menggunakan analisa univariat. Hasil Pengetahuan ibu tentang pijat bayi secara umum sebagian besar kategori cukup sebanyak 16 responden $(53,3 \%)$. Pengetahuan ibu tentang pengertian pijat bayi sebagian besar adalah kategori baik sebanyak 16 responden $(53,3 \%)$. Pengetahuan ibu tentang manfaat pijat bayi sebagian besar adalah kategori sebanyak 14 responden (46,3\%).Pengetahuan ibu tentang cara pemijatan pada bayi sebagian besar adalah kategori kurang sebanyak 14 responden $(46,7 \%)$. Pengetahuan ibu tentang usia yang dianjurkan pijat pada bayi sebagian besar adalah kategori cukup sebanyak 13 responden $(43,4 \%)$.
\end{abstract}

Kata kunci: Pengetahuan, Pijat bayi

\section{LATAR BELAKANG}

Dewasa ini pijat bayi adalah terapi tertua yang dikenal manusia dan yang paling popular. Pijat bayi merupakan tradisi turun temurun yang mampu membantu mengoptimalkan tumbuh kembang bayi. Informasi dan pengetahuan yang kurang, menyebabkan sebagian orangtua beranggapan bahwa pijat bayi dilakukan hanya pada bayi yang sakit serta dilakukan oleh tukang pijat atau tenaga medis yang menguasai pijat. Laporan tertua tentang seni pijat untuk pengobatan tercatat di Papyrus Ebers, yaitu catatan kedokteran pada zaman mesir kuno, di india juga ditemukan AyurVeda, buku kedokteran tertua (sekitar 1800 sebelum masehi ) yang menuliskan tentang pijat, diet, dan olah raga. Selain itu sekitar 5000 tahun yang lalu para dokter di china dari Dinasti Tang meyakini bahwa pijat adalah salah satu dari empat teknik pengobatan yang penting (Roesli, 2013).

Pijat bayi sangat penting dan bermanfaat dilakukan pada bayi $0-3$ bulan dan dapat juga dilakukan pada bayi 3 bulan keatas (Roesli,2013). Meskipun pijat bayi mempunyai manfaat yang besar bagi bayi, namun kenyataannya banyak ibu yang tidak melakukan pemijatan pada bayinya. Salah satu factor yang mempengaruhi ibu dalam melakukan pijat bayi adalah pengetahuan ibu tentang pijat bayi. Pengetahuan merupakan domain yang sangat penting untuk terbentuknya tindakan seseorang.

Berdasarkan penelitian yang pernah dilakukan oleh Yayuk Dwi Haryanti 2015, bahwa tingkat pengetahuan ibu tentang pijat bayi di Dukuh Sambeng, Tadonan, Blora paling banyak kategori cukup yaitu 24 responden $(62 \%)$, sehingga faktor pendorong dan penghambat tingkat pengetahuan ibu tentang pijat bayi yaitu faktor internal yang meliputi pekerjaan, umur, dan faktor eksternal yaitu Lingkungan Sosial budaya

Berdasarkanl wawancara di beberapa bidan jumlah ibu yang memiliki bayi usia 012 bulan 6 orang ibu yang memiliki bayi didapatkan bahwa 4 ibu kurang mengetahui pijat bayi serta belum mengetahui manfaat 
lebih dari pijat bayi dan belum memahami bagaimana memijat bayi yang benar sehingga tidak bisa melakukan pemijatan secara mandiri, 2 ibu mengetahui pengertian dan manfaat pijat bayi. Alasan orang tua memijatkan bayinya ke tukang pijat karena bayi rewel dan terjatuh dan sakit. Mereka mengatakan belum mendapatkan informasi tentang pijat bayi sebelumnya. Sementara itu 2 dari 4 ibu mengatakan takut untuk melakukan pijat bayi karena menurut mereka bayi yang baru lahir tulangnya lembek dan apabila dipijat takut bisa berakibat fatal yaitu patah.

Pijat bayi sangat penting dan bermanfaat dilakukan pada bayi 0-3 bulan dan dapat juga dilakukan pada bayi 3 bulan keatas. (Roesli,2013 ). Meskipun pijat bayi mempunyai manfaat yang besar bagi bayi, namun kenyataannya banyak ibu yang tidak melakukan pemijatan pada bayinya. Salah satu factor yang mempengaruhi ibu dalam melakukan pijat bayi adalah pengetahuan ibu tentang pijat bayi.

Pengetahuan merupakan domain yang sangat penting untuk terbentuknya tindakan seseorang. Apabila prilaku didasari pengetahuan, kesadaran dan sikap positif maka prilaku tersebut akan bersifat langgeng. Sebaliknya jika prilaku itu tidak disadari oleh pengetahuan dan kesadaran maka dampaknya tidak akan berlangsung lama. Pengetahuan ibu tentang pijat bayi yang merupakan yang merupakan alasan utama yang membuat ibu mau membawa bayi untuk melakukan pijat bayi. Hal positif yang ditimbulkan jika ibu melakukan pijat, umumnya bayi akan lebih rileks dan tenang. Melalui sentuhan pemijatan terhadap jaringan otot, peredaran darah dapat meningkat makin lancer dan meningkatkan fungsi-fungsi organ tubuh dengan sebaikbaiknya, meningkatkan berat badan, menjaga pertumbuhan, menjaga daya tahan tubuh, menjaga konsentrasi bayi dan membuat bayi tidur lelap serta membina kasih sayang orang tua dan menjaga produksi ASI (Roesli 2013).

\section{METODE}

Penelitian ini dilaksanakan pada bulan Pebruari-April 2018 di Praktek Mandiri Bidan di Bandar Lampung. Jenis penelitian ini deskritif kuantitatif dengan desain penelitian cross secsional. Populasi penelitian ini adalah seluruh ibu yang mempunyai bayi usia $0-12$ bulan yang berkunjung di bulan Pebruari-April di PMB Bandar Lampung dengan teknik acidental sampling.

Data yang digunakan dalam penelitian ini data primer dan data sekunder. Data sekunder adalah data perkiraan jumlah bayi di PMB, sedangkan data primer adalah data yang diperoleh secara langsung dari sumbernya dan diperoleh dari jawaban atas pernyataan yang disediakan melalui pengisian kuesioner oleh responden. Peneliti memberikan kuesioner secara langsung kepada responden yang sebelumnya di berikan penjelasan maksud dan tujuan penelitian dan peneliti meminta persetujuan berupa informed consent kepada responden.. Jika ada salahsatu responden tidak bersedia maka peneliti memberikan kesempatan responden lainnya yang bersedia dan mempunyai bayi. Penelitian ini berlangsung dari bulan Pebruari-April sesuai jadwal imunisasi di PMB Ny. $\mathrm{N}$ dan di sore serta malam hari setelah responden berobat. Analisis ini dilakukan terhadap tiap variabel dari hasil penelitian. Pada umumnya dalam analisis ini hanya menghasilkan distribusi dan presentasi dari tiap variabel.

\section{HASIL}

Tabel 1: Distribusi Responden Berdasarkan Pengetahuan Ibu tentang Pijat Bayi

\begin{tabular}{lcccc}
\hline \multicolumn{1}{c}{ Variabel } & $\mathrm{n}$ & Min & Maks & Mean \\
\hline $\begin{array}{l}\text { Pengetahuan } \\
\text { ibu tentang }\end{array}$ & 30 & 11 & 26 & 19,7 \\
Pijat bayi & & & & \\
\hline
\end{tabular}


Berdasarkan tabel di atas diketahui rata-rata pengetahuan ibu tentang pijat bayi sebesar $19,7 \%$.

Tabel 2: Distribusi Frekuensi Responden berdasarkan Pengetahuan ibu tentang Pijat Bayi

\begin{tabular}{lcc}
\hline \multicolumn{1}{c}{ Pengetahuan } & $\mathrm{f}$ & $\%$ \\
\hline Baik & 10 & 33,3 \\
\hline Cukup & 16 & 53,3 \\
\hline Kurang & 4 & 13,3 \\
\hline Jumlah & 30 & 100,0 \\
\hline
\end{tabular}

Berdasarkan tabel di atas dapat dilihat bahwa pengetahuan ibu tentang pijat bayi paling banyak pada kategori cukup sebanyak 16 responden $(53 \%)$ dan paling sedikit pada kategori kurang 4 responden $(13,3 \%)$.

Tabel 3: Distribusi frekuensi pengetahuan ibu tentang pengertian pijat bayi

\begin{tabular}{lcc}
\hline \multicolumn{1}{c}{ Pengetahuan } & $\mathrm{f}$ & $\%$ \\
\hline Baik & 16 & 53,3 \\
\hline Cukup & 9 & 30 \\
\hline Kurang & 5 & 16,7 \\
\hline Jumlah & 30 & 100 \\
\hline
\end{tabular}

Berdasarkan tabel di atas diketahui bahwa pengetahuan ibu tentang pengertian pijat bayi di PMB Nurmala Dewi Rajabasa Bandar Lampung sebagian besar adalah kategori baik sebanyak 16 responden $(53,3 \%)$.

Tabel 4: Distribusi frekuensi pengetahuan ibu tentang manfaat pijat bayi secara umum

\begin{tabular}{lcc}
\hline \multicolumn{1}{c}{ Pengetahuan } & f & $\%$ \\
\hline Baik & 7 & 23,3 \\
\hline Cukup & 14 & 46,7 \\
\hline Kurang & 9 & 30 \\
\hline Jumlah & 30 & 100 \\
\hline
\end{tabular}

Berdasarkan Tabel 4 diketahui bahwa pengetahuan ibu tentang manfaat pijat bayi di BPM Nurmala Dewi Rajabasa Bandar Lampung sebagian besar adalah kategori cukup sebanyak 14 responden (46,3\%).

Tabel 5: Distribusi frekuensi pengetahuan ibu tentang Usia yang dianjurkan pijat bayi

\begin{tabular}{lcc}
\hline \multicolumn{1}{c}{ Pengetahuan } & f & $\%$ \\
\hline Baik & 10 & 33,3 \\
\hline Cukup & 13 & 43,4 \\
\hline Kurang & 7 & 23,3 \\
\hline Jumlah & 30 & 100 \\
\hline
\end{tabular}

Berdasarkan tabel di atas diketahui bahwa pengetahuan ibu tentang usia yang dianjurkan pijat bayi di PMB Nurmala Dewi Rajabasa Bandar Lampung sebagian besar adalah kategori cukup sebanyak 13 responden $(43,4 \%)$.

Tabel 6: Distribusi frekuensi tingkat pengetahuan ibu tentang tehnik pijat bayi

\begin{tabular}{lcc}
\hline \multicolumn{1}{c}{ Pengetahuan } & f & $\%$ \\
\hline Baik & 6 & 20 \\
\hline Cukup & 10 & 33,3 \\
\hline Kurang & 14 & 46,7 \\
\hline Jumlah & 30 & 100 \\
\hline
\end{tabular}

Berdasarkan tabel di atas diketahui bahwa pengetahuan ibu tentang tekhnik yang dianjurkan pijat bayi di PMB Nurmala Dewi Rajabasa Bandar Lampung sebagian besar adalah kategori Kurang sebanyak 14 responden $(46,7 \%)$.

\section{PEMBAHASAN}

\section{Pengetahuan Ibu Tentang Pijat Bayi}

Berdasarkan hasil penelitian tentang gambaran pengetahuan ibu tentang pijat bayi di PMB Nurmala Dewi Rajabasa Bnandar Lampung. Ibu yang mempunyai bayi dan 
berkunjung di PMB Nurmala Dewi Rajabasa Bandar Lampung yang paling banyak pengetahuan yang cukup tentang pijat bayi yaitu sebanyak 16 responden (53\%) dan paling sedikit 4 responden $(13,3 \%)$.mempunyai pengetahuan kurang tentang pijat bayi.

Pengetahuan adalah hasil tahu dan ini terjadi setelah orang melakukan pengindraan terhadap suatu objek tertentu (Notoatmodjo, 2011) Berdasarkan hasil penelitian tingkat pengetahuan responden paling banyak yaitu berpengetahuan cukup. Faktor-faktor yang mempengaruhi pengetahuan responden antara lain informasi, kultur (budaya), pendidikan dan pengalaman, sosial ekonomi dan uisa menurut Notoatmodjo (2011)

Pijat bayi adalah pengungkapan rasa kasih sayang antara orang tua dengan anak lewat sentuhan kulit yang dapat memberikan dampak yang luar biasa (Dewi, 2012). Manfaat pijat bayi diantaranya dapat meningkatkan pertumbuhan dan berat badan bayi, meningkatkan efektivitas istirahat (tidur),meningkatkan daya memacu perkembnagan otak dan saraf, meningkatkan aliran oksigen dan nutrisi menuju sel, membina hubungan orang tua dan anak, dan dapat meningkatkan volume ASI (Roesli, 2013).

Menurut peneliti, Pengetahuan ibu tentang pijat bayi memungkinkan karena sudah pernah mendaptkan informasi tentang pijat bayi dari penyuluhan yang pernah dilaksanakan oleh bidan. Pengetahuan ibu tersebut tidak terlepas dari tingkat pendidikan, usia dan pekerjaan. Semakin tinggi pendidikan maka ibu akan mudah menerima dan menyesuaikan diri dengan hal-hal yang baru. Berdasarkan Pengalaman, beberapa orang ibu sebelumnya pernah membawa anak nya ke tempat spsialis pijat bay, dan pekerjaan dapat mempengaruhi pengetahuan lingkungan pekerjaan. Di PMB Nurmala Dewi ada salasatu ibu mempunyai bayi yang suda pernah mengikuti pelatihan pijat bayi yang diselengrakan oleh puskesmas. Sebagian besar Ibu tidak bekerja, ibu akan banyak memiliki waktu luang untuk meningkatkan pengetahuan maupun pengalaman dengan mengakses informasi baik dari media online, seperti sosial media instragram. Banyak ibuibu yang menggunakan akun sosial media untuk mencari tau informasi tentang pijat bayi.

\section{Pengetahuan Ibu Tentang Pengertian Pijat Bayi}

Berdasarkan dari hasil penelitian yang dilakukan, dan 30 responden bahwa pengetahuan ibu tentang pengertian pijat bayi yang di lakukan di PMB Nurmala Dewi Rajabasa Bandar Lampung adalah kategori baik sebanyak 16 responden (53\%).

Pijat bayi disebut sebagai stimulus touch. Pijat bayi dapat diartikan sebagai sentuhan komunikasi yang nyaman antara ibu dan bayi. Jadi pijat bayi ini merupakan suatu pengungkapan rasa kasih sayang antara orang tua dan anak lewat sentuhan pada kulit yang dapat yang dapat memberikan dampak sangat luar biasa. Hal ini karena, sentuhan-sentuhan dan pelukan merupakan salahsatu kebutuhan dasar bayi (Siska Dewi, 2016).

\section{Pengetahuan Ibu Tentang Manfaat Pijat Bayi}

Berdasarkan analisis dari hasil penelitian yang dilakukan, dan 30 responden bahwa pengetahuan ibu tentang pengertian pijat bayi yang di lakukan di PMB Nurmala Dewi Rajabasa Bandar Lampung adalah kategori cukup sebanyak 14 responden $(46,3 \%)$.

Pengetahuan ibu tentang manfaat pijat bayi menunjukan bahwa sudah cukup mengetahui apa saja manfaat pijat bayi. Beberapa manfaat pijat bayi yaitu membuat ibu dan bayi semakin tenang dan nyaman, meningkatkan pertumbuhan dan berat badan bayi, meningkatkan efektivitas istirahat (tidur) dan konsentrasi bayi pijat bayi dapat menyebabkan bayi lebih rileks dan dapat bersistirahat dengan efektif, meningkatkan daya tahan tubuh, memacu perkembangan otak dan sistem saraf, meningkatkan aliran 
oksigen dan nurtisi menuju sel, membina kasih sayang orang tua dengan anak (Alissa Putri, 2009).

\section{Pengetahuan Ibu Tentang Usia Dianjurkan Pijat Bayi}

Berdasarkan analisis dari hasil penelitian yang dilakukan, dan 30 responden bahwa pengetahuan ibu tentang usia pijat bayi yang di lakukan di BPM Nurmala Dewi Rajabasa Bandar Lampung adalah kategori Cukup sebanyak 13 responden $(43,4 \%)$. Usia bayi 0-1 bulan disarankan gerakan yang lebih mendekati usapan-usapan halus. Jika tali pusat bayi belum lepas, sebaiknya tidak dilakukan pemijatan di daerah perut. 1-3 bulan, disarankan gerakan halus disertai dengan tekanan ringan dalam waktu yang singkat . 3 bulan-3 tahun, disarankan seluruh gerakan dilakukan dengan tekanan dan waktu yang semakin meningkat. Total waktu pemijatan disarankan sekitar 15 menit (Utami Roesli, 2014).

\section{Pengetahuan Ibu Tentang Tekhnik Pijat Bayi}

Berdasarkan analisis dari hasil penelitian yang dilakukan, dan 30 responden bahwa pengetahuan ibu tentang tekhnik pijat bayi yang di lakukan di PMB Nurmala Dewi Rajabasa Bandar Lampung adalah kategori kurang sebanyak 14 responden $(46,7 \%)$. Pengetahuan ibu kurang tentang cara memijat bagian kaki punggung dan dada bayi. Secara umum, pemijatan sebaiknya dimulai dari kaki bayi, permulaan seperti ini akan memberi kesempatan pada bayi untuk membiasakan dipijat sebelum bagian luar disentuh. Itu sebabnya urutan pemijatan bayi dianjurkan dimulai dari bagian kaki, kemudian perut, dada tangan muka, dan diakhiri pada bagian punggung (Prasetyono 2009). Hands on baby massase adalah salahsatu penyedia terkemuka dari royal collage of midwives yang terakreditasi, yang menawarkan kursus pelatihan baby yoga dan kelas pijat bayi di lokasi nyaman diseluruh inggris. Baby massase adalah salah satu dari banyak tradisi kuno yang dapat membantu ibu baru,tua dan lama dalam memberikan bayi mereka kemungkinan awal kehidupan yang terbaik.

\section{KESIMPULAN}

Hasil penelitian secara umum menyimpulkan bahwa sebagian besar pengetahuan ibu tentang pijat bayi cukup $(53,3 \%)$. Bila dijabarkan lebih lanjut, maka sebagian besar pengetahuan ibu tentang pengertian pijat bayi baik $(53,3 \%)$, tentang manfaat pijat bayi cukup $(46,7 \%)$, tentang usia pijat bayi cukup $(43,4 \%)$ dan tentang teknik pijat bayi kurang $(46,7 \%)$.

Berdasarkan hasil itu disarankan agar tempat pelayanan dapat meningkatkan mutu pelayanan dan sebagai bahan masukan dalam meningkatkan pemberian konseling tentang manfaat pijat bayi.

\section{DAFTAR PUSTAKA}

Haryanti, Y.D. (2015). Tingkat Pengetahuan Ibu tentang Pijat Bayi di Dukuh Sambeng Desa Sambeng Todanan Blora. Laporan Tugas Akhir. STIKES Kusuma Husada Surakarta.

Notoatmodjo, Soekidjo. (2011). Promosi Kesehatan dan Perilaku Kesehatan, Jakarta: Rineka Cipta

Prasetyono. (2009). Buku Pintar ASI Eksklusif. Jogjakarta : Diva Pres.

Putri, Alissa. (2009). Pijat dan Senam Untuk Bayi dan Balita Panduan Praktis Memijat Bayi dan Balita. Yogyakarta: Brilliant Offset

Roesli Utami. (2013). Pedoman Pijat Bayi. Jakarta: Trubus Agriwidya 